\title{
Immobilized Enzyme Reactors Based on Nucleoside Phosphorylases (NPs) and Nucleoside 2'- Deoxyribosyltransferases (NDTs) for the In-Flow Synthesis of Nucleoside Analogues ${ }^{\dagger}$
}

\author{
Marco Terreni *, Francesca Rinaldi, Caterina Temporini, Enrica Calleri, Gabriella Massolini \\ and Daniela Ubiali \\ Department of Drug Sciences, University of Pavia, 27100 Pavia, Italy; \\ francesca.rinaldi01@universitadipavia.it (F.R.); caterina.temporini@unipv.it (C.T.); \\ enrica.calleri@unipv.it (E.C.); g.massolini@unipv.it (G.M.); daniela.ubiali@unipv.it (D.U.) \\ * Correspondence: marco.terreni@unipv.it \\ + Presented at the 2nd Molecules Medicinal Chemistry Symposium (MMCS): Facing Novel Challenges in \\ Drug Discovery, Barcelona, Spain, 15-17 May 2019.
}

Published: 21 November 2019

Enzymes are increasingly used as biocatalysts for the production of Active Pharmaceutical Ingredients and fine chemicals [1,2]. A well-known strategy to increase enzyme stability and to allow the reuse of biocatalysts for multiple cycles is immobilization. Moreover, when flow systems are employed for biocatalyzed reactions, the process can benefit from accurate control of the reaction parameters, improved mass transfer, and reduction of substrate/product inhibition effects [3].

Immobilized enzyme reactors (IMERs) can be successfully applied in drug discovery for the rapid preparation of chemical libraries. In addition, single or multi-enzyme IMERs can be connected to different separation and detection systems.

In this work, two analytical IMERs were developed as prototypes for biosynthetic purposes, and their performances in the in-flow synthesis of nucleoside analogues of pharmaceutical interest were evaluated. Two classes of enzymes were tested: nucleoside phosphorylases (NPs) and nucleoside 2'deoxyribosyltransferases (NDTs).

The NP-based bioreactor was prepared by co-immobilizing uridine phosphorylase from Clostridium perfringens ( $\mathrm{C} P \mathrm{UP}$ ) and a purine nucleoside phosphorylase from Aeromonas hydrophila (AhPNP) on an aminopropyl silica column [4], while the second IMER was obtained by covalent immobilization of nucleoside 2'-deoxyribosyltransferase from Lactobacillus reuteri (LrNDT) on an epoxy silica column. As the chromatographic support, a monolithic material (Chromolith ${ }^{\circledR}$ columns) $^{-}$ was selected due to its low operative back-pressure and fast mass transfer.

The in-flow synthesis of 5-iodo-2'-deoxyuridine, 5-fluoro-2'-deoxyuridine, and 2', $3^{\prime}$ dideoxyinosine was then performed by exploiting both $C p \mathrm{UP} / A h \mathrm{PNP}-$ and LrNDT-IMERs. Reaction monitoring and conversions were assessed by a reverse phase liquid chromatography system coupled to UV detection. LrNDT-IMER allowed to achieve higher conversions in shorter times for the investigated reactions.

\section{References}

1. Truppo, M.D. Biocatalysis in the pharmaceutical industry: The need for speed. ACS Med. Chem. Lett. 2017, $8,476-480$.

2. Sheldon, R.A.; Woodley, J.M. Role of biocatalysis in sustainable chemistry. Chem. Rev. 2018, 118, 801-838. 
3. Tamborini, L.; Fernandes, P.; Paradisi, F.; Molinari, F. Flow bioreactors as complementary tools for biocatalytic process intensification. Trends Biotechnol. 2018, 36, 73-88.

4. Cattaneo, G.; Rabuffetti, M.; Speranza, G.; Kupfer, T.; Peters, B.; Massolini, G.; Ubiali, D.; Calleri, E. Synthesis of adenine nucleosides by transglycosylation using two sequential nucleoside phosphorylasebased bioreactors with on-line reaction monitoring by using HPLC. Chem CatChem 2017, 9, 4614-4620.

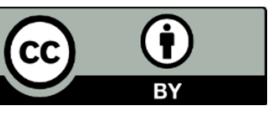

(C) 2019 by the authors. Licensee MDPI, Basel, Switzerland. This article is an open access article distributed under the terms and conditions of the Creative Commons Attribution (CC BY) license (http://creativecommons.org/licenses/by/4.0/). 